\title{
Estrategias de marketing de un cine ubicado en un sector de nivel socio económico bajo en Ecuador
}

\section{Marketing strategies of a cinema located in a sector of low socioeconomic level in Ecuador}

Stefanie Alexandra Flores González

Universidad Ecotec, Ecuador

Autor por Correspondencia: stefanie_flores@hotmail.com, sflores@ecotec.edu.ec Fecha de recepción: 08 de Agosto 2017 - Fecha de aceptación: 15 de Enero de 2018

Resumen: La presente investigación tiene como objetivo proponer estrategias de marketing para un complejo de cines con alta tecnología, ubicado en una zona de población de nivel socioeconómico bajo y medio bajo en la ciudad de Guayaquil-Ecuador. Su alto crecimiento en ventas resulta interesante, considerando que este tipo de entretenimiento no es la opción más económica para este mercado y que, dadas las restricciones en ingresos de la población cercana, no se esperaba una reacción favorable de manera inmediata. Mediante encuestas a una muestra de la población de clientes del cine y entrevistas a profundidad, se obtuvo la información requerida sobre el perfil del consumidor, su percepción sobre el servicio, reconocimiento, aceptación de la marca y los motivadores actuales de compra. Los resultados de esta investigación favorecen a la definición de estrategias de marketing para esta nueva marca de cines en Guayaquil.

Palabras claves: estrategias; cine; marketing; marca

Abstract: The purpose of this investigation is to recommend marketing strategies for a high technology cinema theater, which is located in a low- and medium-low socioeconomic population in the city of Guayaquil-Ecuador. The high sales growth for this segment of the market is unusual, considering that this type of entertainment is not the most economical option for this market. In addition, given the restrictions on incomes for this segment, a favorable reaction was not expected immediately. The surveys and in-depth interviews conducted to the cinema clients, showed the consumer profile, their perception about the service, their recognition and acceptance of the brand and their current motivators of purchase. The results of this research favor the developing of marketing strategies for this new brand of movie theaters in Guayaquil.

Key words: strategies; movie theater; marketing; brand 


\section{Introducción}

Los consumidores toman muchas decisiones de compra todos los días. La mayor parte de las empresas grandes investigan las decisiones de compra de los consumidores con gran detalle para descubrir qué compran los consumidores, dónde lo compran, cómo y cuánto compran, cuándo lo hacen y por qué lo hacen (Kotler \& Amstrong, 2001, pág. 137). Entender al consumidor y la mayor parte de los factores que afectan su compra como los culturales, sociales, personales y psicológicos, propuestos también por los autores mencionados, generan una oportunidad a las empresas de adaptarse a la situación real de sus mercados, desarrollando productos y servicios deseados, a precios que estén dispuestos a pagar, en el lugar que el cliente desee comprar y comunicado de manera efectiva.

El consumidor se ha vuelto el centro de atención de todas las empresas de productos y servicios, siendo ahora él quien establece cuales son las preferencias y necesidades que las diferentes marcas deben satisfacer, esto sucede porque el mercado ha ido evolucionado, teniendo cada vez más acceso a la información, por tanto, más poder de negociación.

El marketing ha pasado de centrar sus actividades en la venta de productos (marketing 1.0), a orientarse a entender y satisfacer las necesidades del consumidor (marketing 2.0) llegando incluso a un marketing 3.0 que se basa en los valores humanos, ayudando a lograr un mundo mejor a través de todos los actores que participan en el crecimiento de la empresa como los consumidores, proveedores, empleados y otros individuos (Armstrong \& Kotler, 1996).

Los mercados se han vuelto altamente competitivos, por tanto las empresas deben al menos llegar a una estrategia de marketing 2.0 y encontrar un atributo diferenciador valorado por el cliente que conlleve a su elección y preferencia. Levy (1998) destaca que aquel conjunto percibido (marca) que le "signifique" al consumidor la configuración de atributos más parecida al conjunto esperado, ha de ser el que logre más motivación por ser elegido (p. 334). Se puede lograr el conocimiento de los atributos diferenciadores en base a investigaciones de mercado, las cuales se proponen en este artículo para una nueva marca de complejos de cine.

Max Cinema, es una nueva marca de cines en la ciudad de Guayaquil-Ecuador, cuyas instalaciones se encuentran ubicadas en un sector donde sus habitantes tienen limitaciones económicas, a pesar de ello, sus ventas han crecido más de los esperado, lo que provoca un interés en encontrar cuáles son los atributos valorados por los clientes actuales, que permitan establecer parámetros estratégicos de diferenciación.

Si analizamos una de las teorías psicológicas que afectan el comportamiento de compra de los consumidores, Alonso \& Grande (2004) nos presentan la jerarquía de las necesidades de Abraham Maslow (enfoque humanístico-existencial), que sugiere que las necesidades del consumidor son satisfechas en orden pasando desde las más básicas como las fisiológicas, de seguridad, sociales, de estima hasta alcanzar la autorealización (p.60). Si los consumidores reaccionaran ante las compras de esta manera, el mercado meta del cine debería haber priorizado las necesidades base, dejando al entretenimiento (que corresponde al tercer escalón dentro de las necesidades sociales) como una de las menos prioritarias afectando las ventas de esta marca, sin embargo no fue así. 
Dada la naturaleza poco lógica de las decisiones de compra de los consumidores, se desarrolla esta investigación, estudio que permitió encontrar el perfil del consumidor meta, reconocer el o los atributos que podrían diferenciarlos de la competencia, la aceptación de marca, percepción sobre ella, motivadores internos de compra y otras variables importantes para el planteamiento de la estrategia de marketing para esta nueva marca de cines.

\section{Métodos}

Se aplicaron dos tipos de investigación: Concluyente mediante el método cuantitativo y exploratoria usando el método cualitativo. Para la investigación cuantitativa se decidió usar la técnica de encuestas, se aplicó entonces un muestreo aleatorio de la población de consumidores que asistieron al cine durante una semana completa considerando fines de semana, el cuestionario tomó en consideración indicaciones de formulario de Arribas (2004).

La muestra para la investigación se la obtuvo de la fórmula para una población finita, considerando un error muestral del $4,98 \%$, un nivel de confianza del $95 \%$ y una población aproximada de 25000 personas que asisten mensualmente a este cine, lo que dio como resultado un total de 382 personas a encuestar, desglose que se puede destacar a continuación:

$$
\begin{aligned}
& \mathbf{n}=\frac{Z^{2} \cdot \text { p. q. } N}{N^{2}+Z^{2} \text { p. q. }} \\
& Z=\text { Nivel de confianza } \\
& \mathrm{N}=\text { Población-Censo } \\
& \mathrm{p}=\text { Probabilidad } \mathrm{a} \text { favor } \\
& q=\text { Probabilidad en contra } \\
& \mathrm{e}=\text { error de estimación } \\
& \mathrm{n}=\text { Tamaño de la muestra }
\end{aligned}
$$

Tabla 1

\begin{tabular}{ll}
\hline Población & $\mathbf{2 5 0 0 0}$ \\
\hline $\mathbf{P}$ & 0,5 \\
e (margen de error muestral) & $4,98 \%$ \\
nivel de confianza & $95,00 \%$ \\
Nivel de significancia & $5 \%$ \\
$\mathbf{Z}$ & 1,960 \\
TAMAÑO MUESTRAL POBLACION FINITA & 382 \\
\hline
\end{tabular}

Fuente: Análisis autora

En pro de conseguir información más exhaustiva del comportamiento del consumidor de esta marca de cines, se decidió realizar una investigación cualitativa usando la técnica de entrevista a profundidad al tipo de consumidor que presente a la mayoría de la población del cine, dato que se obtendrá de la investigación cuantitativa. La técnica de entrevista a profundidad según (Malhotra, 2004), permite libre intercambio de información lo que no se logra fácilmente en grupos de enfoque porque por razones sociales puede existir el cambio de criterio de uno o varios de los participantes para sentirse de acuerdo con el grupo. El objetivo que persigue este tipo de análisis es aportar con información extra con los cuales se identifiquen los motivadores de compra, posibles influenciadores o en su defecto posibles barreras que no ayuden a generar más compras en el cine. 
El análisis de los resultados obtenidos en ambas investigaciones propuestas para este proyecto, permitirán tener una visión más completa de los reales consumidores del cine y sus preferencias, sirviendo así de base para la planificación de marketing que permitirá una posible diferenciación.

\section{Resultados Investigación Cuantitativa}

\section{Resultados}

Mediante gráficos y tablas se presentan los resultados obtenidos de las encuestas realizadas a los consumidores del cine Max Cinema, los cuales permitieron determinar un perfil del consumidor frecuente, sus preferencias, percepciones y datos adicionales que proporcionaron una base para el desarrollo de las estrategias de marketing.

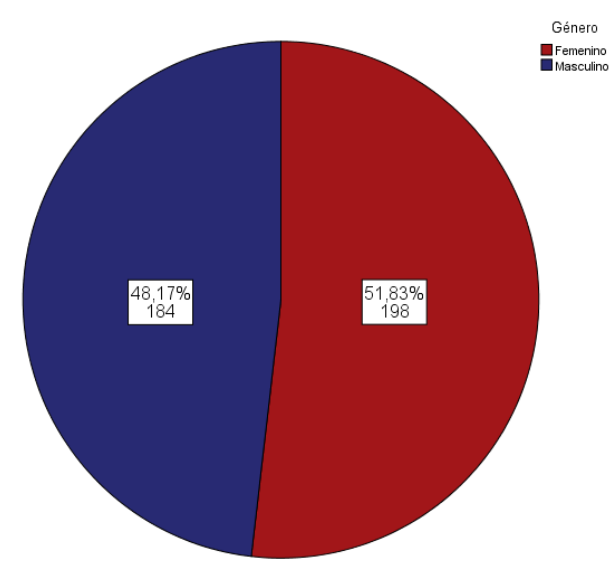

Figura 1: Género de los consumidores

La cantidad de personas encuestadas y que visitan al cine distribuidos por géneros están en un $48,17 \%$ hombres y $51,83 \%$ mujeres.

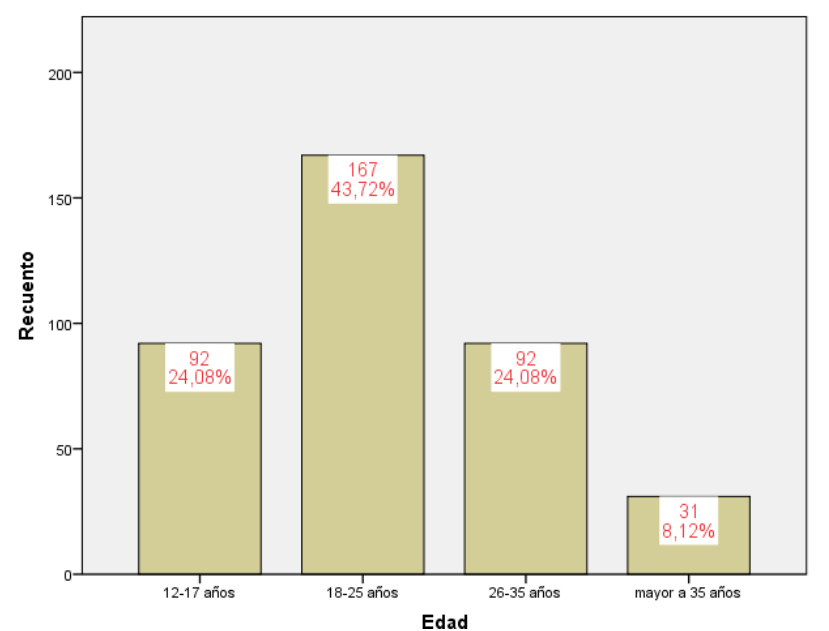

Figura 2: Distribución edades de la muestra de consumidores

La edad de los consumidores encuestados está representada en su mayoría por un 43,70\% de personas entre 18 a 25 años, seguida del 24,10\% de 26 a 35 años, 24,10\% de 12 a 17 años y por último $8,10 \%$ mayores a 35 años. 


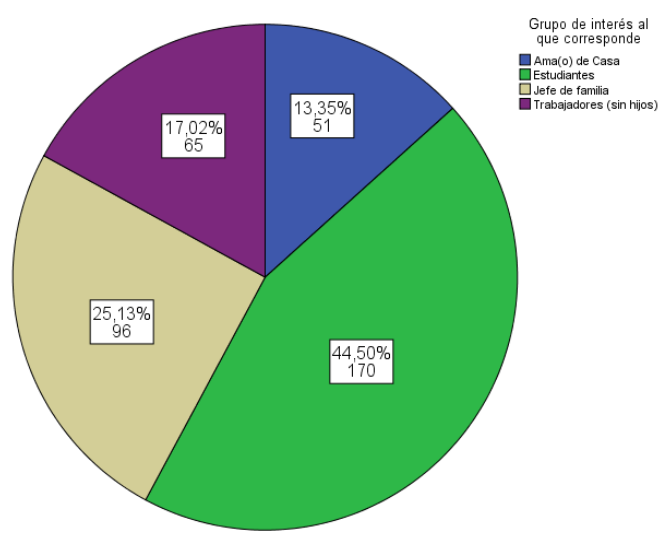

Figura 3: Grupo de Interés al que corresponde

Se encontró que el 44,50\% de los encuestados son estudiantes sin hijos, el 25,13\% Jefes de familia, el 17,02\% trabajadores sin hijos y el 13,35\% Amas de casa.

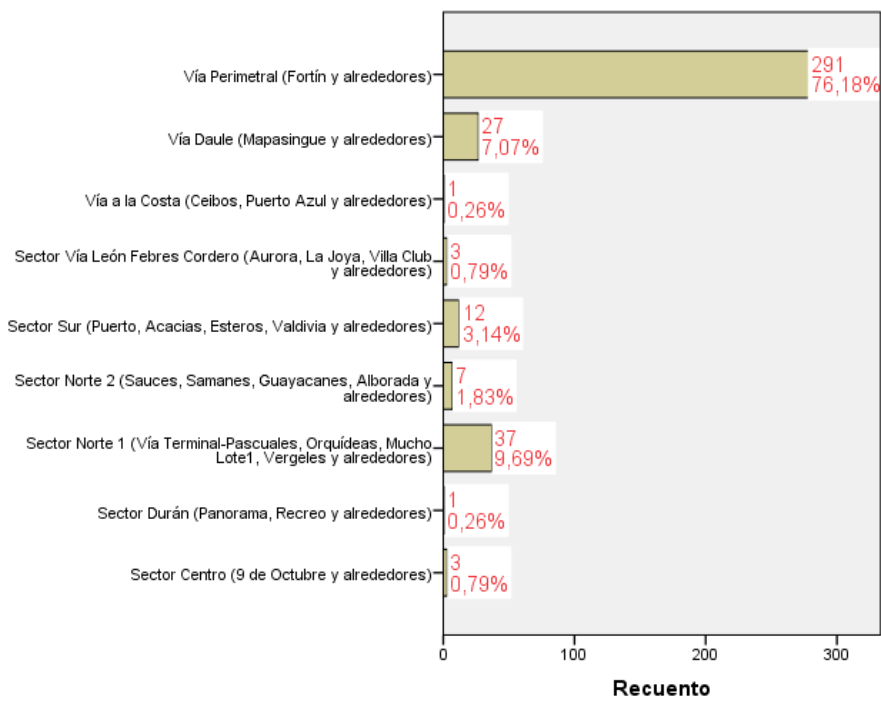

Figura 4: Sector donde vive

Dentro de las zonas de residencia se puede destacar que el 76,18\% viven en zonas aledañas al Fortín, el 9,69\% Sector norte 1 (Terminal-Pascuales, Orquídeas, Mucho Lote, Vergeles y alrededores), el 7,07\% Vía a Daule (Mapasingue y alrededores), y el 7\% otras zonas como sur, norte 2 (Sauces, Samanes, Guayacanes, Alborada y alrededores), Vía León Febres Cordero, Durán, centro y Vía a la Costa). 

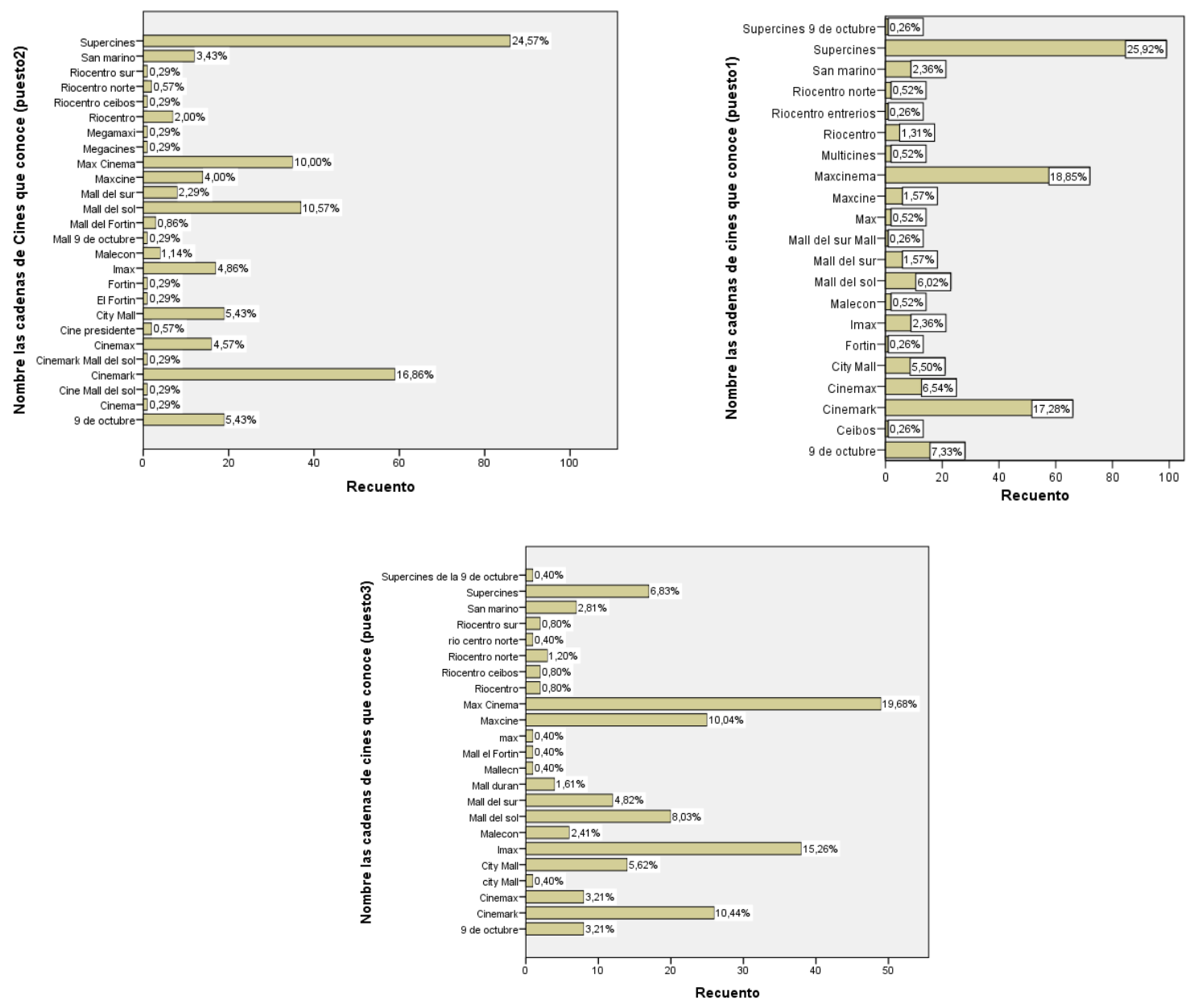

Figura 5: Nombre de los cines que conoce, primer, segundo y tercer puesto

A los encuestados se los cuestionó respecto a los nombres de cines que conocen, tomando en cuenta el orden se destaca que el 25,92\% mencionó a Supercines en primer lugar, el 24,57\% también nombró a Supercines en segundo lugar y el 19,68\% nombró a Max Cinema en tercer lugar.

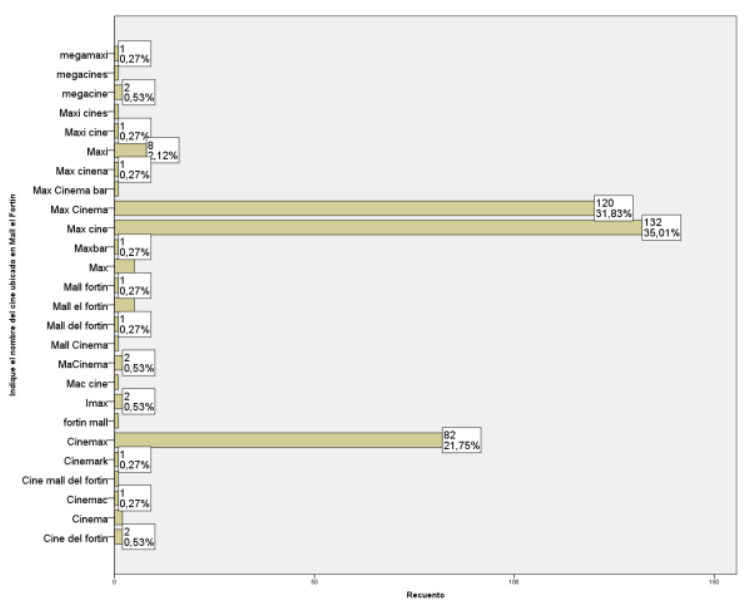

Figura 6: Nombres del cine ubicado en Mall El Fortín 
El gráfico 6 destaca que el 35,01\% de los encuestados piensa que el nombre del cine es "Max Cine", el 31,83\% lo menciona como "Max Cinema" y el restante le da otros nombres variantes del nombre real.

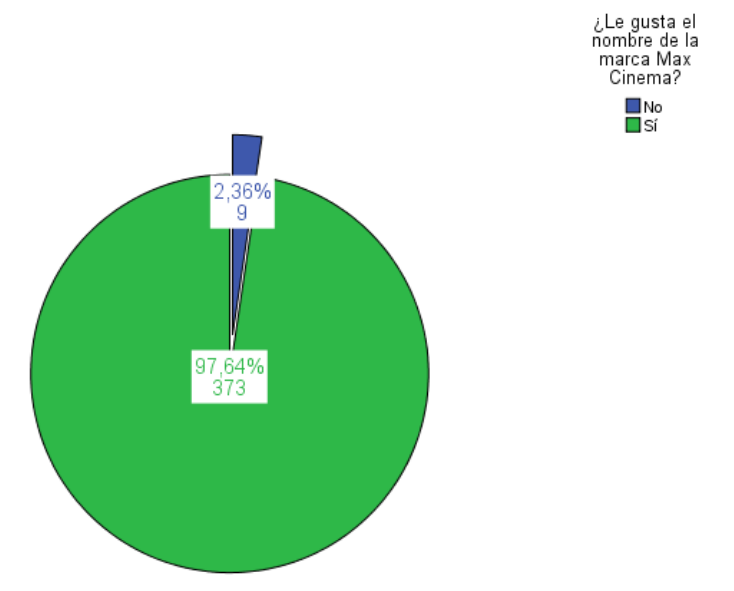

Figura 7: Les gusta el nombre de la marca Max Cinema

El 97,64\% de los encuestados afirman que les gusta el nombre de la marca de cines Max Cinema mientras el 2,36\% menciona que no le gusta.
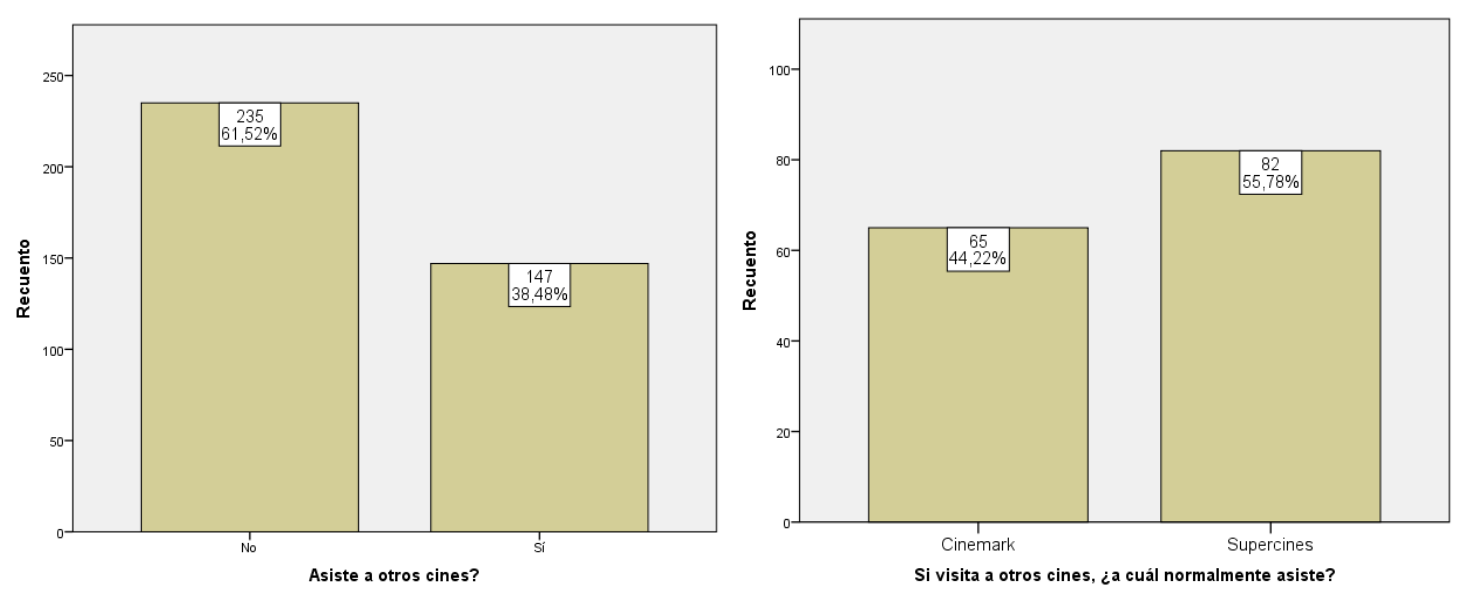

Figura 8: Asiste a otros cines

El 61,52\% de los encuestados afirman que no asisten a otros cines además de Max Cinema y el 38,48\% dijo que sí lo hace. Del total de los que mencionaron que sí asisten a otros cines se puede destacar que el 55,78\% mencionó que asiste a Supercines mientras el 44,22\% a Cinemark. 


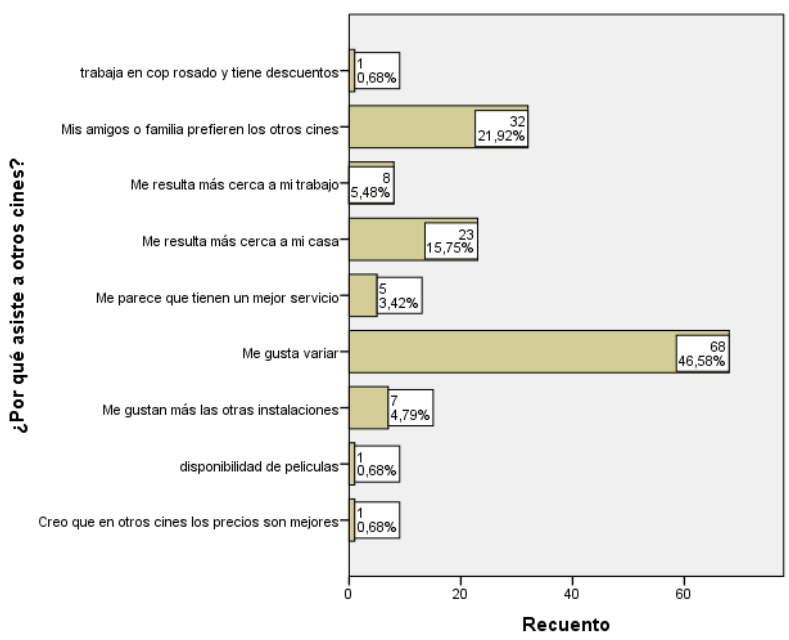

Figura 9: Por qué asiste a otros cines

Entre las razones por las cuales los encuestados que afirmaron ir a otros cines suelen ir se destaca un 46,58\% que dice que le gusta variar de cines, seguido del 21,92\% que mencionan que sus amigos o familia prefieren ir a otros cines, el $15,75 \%$ porque le resulta más cerca a su casa, el $5,48 \%$ porque los otros cines se encuentran más cerca de sus trabajos, el 4,79\% que le gustan más las otras instalaciones, el 3,42\% que les parece que en otros cines tienen un mejor servicio, y un $0,68 \%$ porque trabajan para el grupo de empresas propietaria de Supercines, $0,68 \%$ por la disponibilidad de películas en otros lados y por último el $0,68 \%$ cree que en los otros cines los precios son mejores.

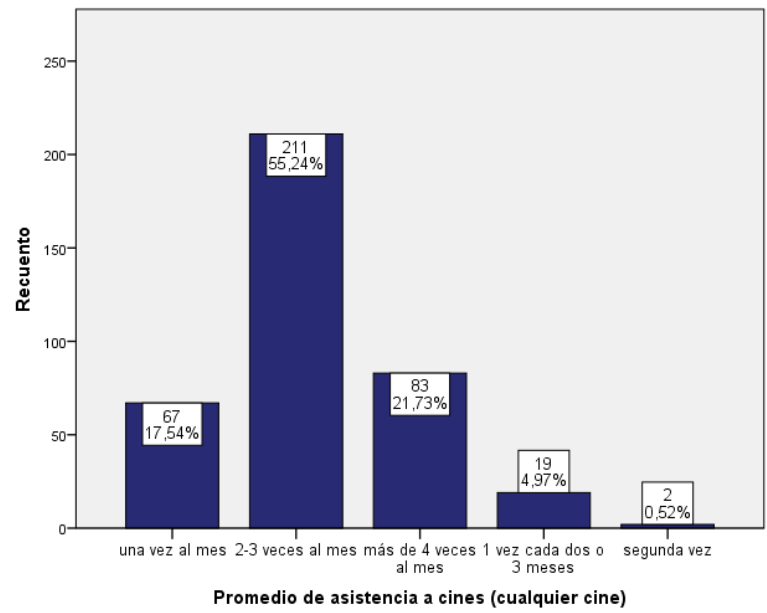

Figura 10: Promedio de asistencia a cualquier cine

El 55, 24\% de los encuestados asegura asistir a cines entre dos a tres veces al mes, el 21,73\% más de cuatro veces al mes, el 17,54\% una vez al mes, seguido del 4,97\% que asiste con menos frecuencia siendo de una vez cada dos o tres meses y un $0,52 \%$ que era la segunda vez que visitaba un cine. 


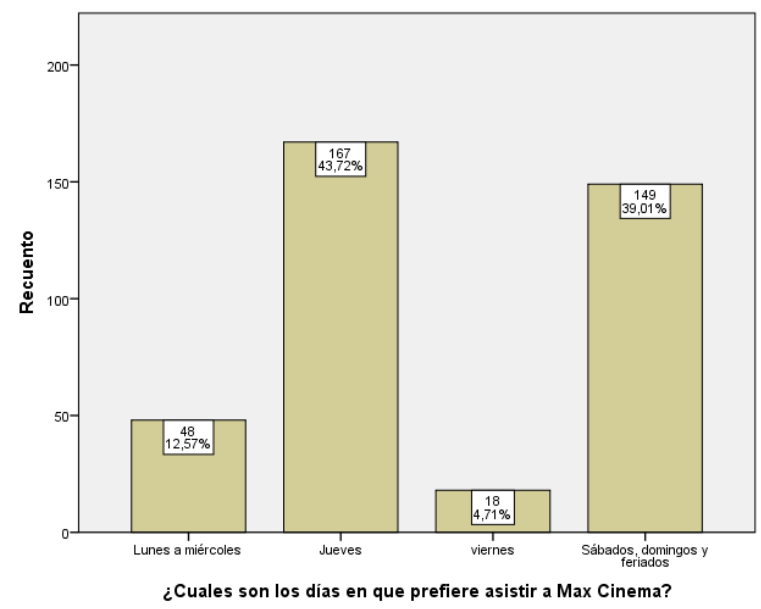

Figura 11: Días preferidos de asistencia

Respecto a los días de preferencia para asistir a Max Cinema se encontró en primer lugar al día jueves con el $43,72 \%$ de preferencia, seguido del 39,01\% que son los fines de semana y feriados, $12,57 \%$ de lunes a miércoles y $4,71 \%$ los viernes.

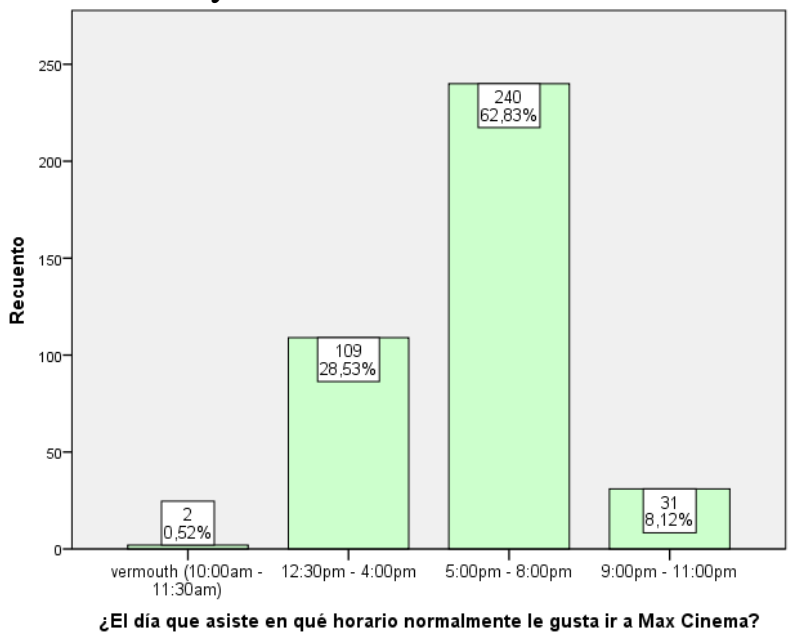

Figura 12: Horario en que le gusta asistir a Max Cinema

El 62,83\% prefiere asistir de 5:00pm a 8:00pm destacándose como la mayor preferencia, seguido de un 28,53\% de 12:30 a 4:00pm, un 8,12\% de 9:00pm a 11:00pm y finalmente un $0,52 \%$ en horarios de vermouth que corresponde de 10:00am a 11:30am. 


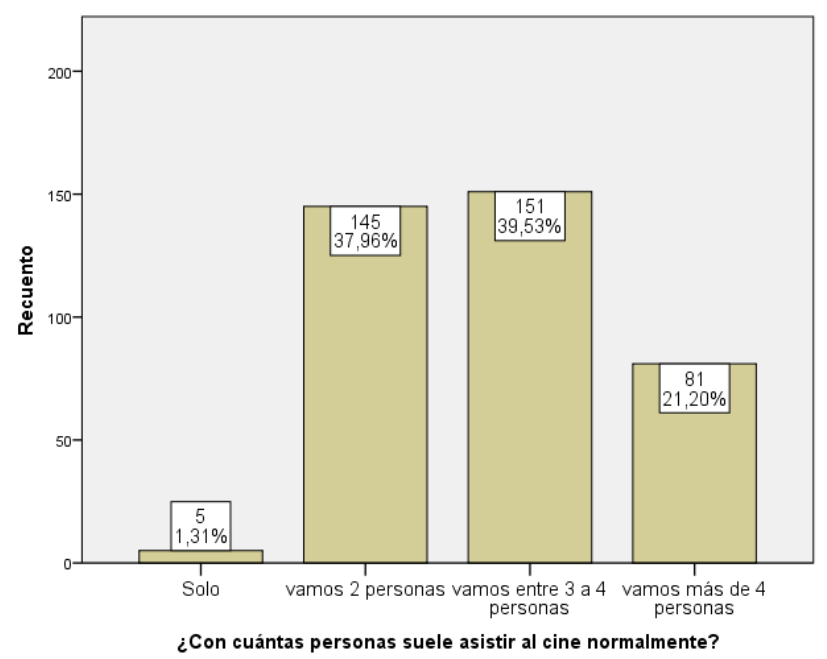

Figura 13: Cantidad de personas con las que suele asistir a Max Cinema

Consultando sobre la cantidad de personas con las que el encuestado suele ir al cine, se puede destacar que el 39,53\% afirma venir entre 3 a 4 personas, el 37,96\% asisten dos personas, el $21,20 \%$ más de 4 personas y un 1,31\% que acuden solos.

Era importante conocer también la disponibilidad a pagar que tienen los clientes del cine tanto en entradas como en comida del bar dependiendo de la cantidad de personas con las que asistían, se les consultó y se obtuvieron las siguientes respuestas (Ver anexo 4 los datos recogidos de la encuesta):

- Disponibilidad máxima a pagar en entradas para películas 2D: El 59,42\% estarían dispuestos a cancelar entre $\$ 4$ a $\$ 5,50$, el $37,17 \%$ entre $\$ 2$ a $\$ 3,50$, el 2,62\% entre $\$ 5,50$ a $\$ 6$ y el $0,79 \%$ entre $\$ 6$ a $\$ 7$.

- Disponibilidad máxima a pagar en entradas para películas 3D: El 58,12\% de las personas indicaron que cancelarían entradas entre $\$ 5,50$ a $\$ 6$, el $24,87 \%$ entre $\$ 4$ a $\$ 5,50$, el $16,75 \%$ entre $\$ 6$ a $\$ 7$ y el $0,25 \%$ entre $\$ 2$ a $\$ 3,50$.

- Disponibilidad a cancelar en comida del bar: El 37,43\% mencionó que su disponibilidad a cancelar en alimentos del bar está entre \$10 a \$20, seguido del $35,34 \%$ que cancelaría entre $\$ 8$ a $\$ 9$, el $15,97 \%$ más de $\$ 20$, el $9,16 \%$ entre $\$ 5$ a $\$ 7$ y por último el 2,09\% de $\$ 0$ a $\$ 3,50$.

Esto nos permite destacar que al menos un poco más de la mitad de los encuestados están acostumbrados a cancelar los precios normales en entradas 2D ( $\$ 4$ a $\$ 5,50)$, sin embargo en las entradas 3D no ocurre lo mismo, siendo el precio normal aproximadamente $\$ 7$, la disponibilidad máxima a cancelar expresada en su mayoría $(58,12 \%)$ estuvo entre los $\$ 5,50$ a $\$ 6$. Respecto a la disponibilidad a consumir en productos del bar se destaca que un 88,74\% está dispuesto a cancelar más de $\$ 8$ en comida del bar lo cual resulta atractivo para un negocio como el cine.

Se realizó una consulta adicional respecto a los precios de este cine, pues resulta importante conocer la percepción que el consumidor tiene sobre este particular, por lo que se solicitó a los encuestados calificar los precios tanto de boletería y bar en las categorías de Muy 
económicos, Económicos, Ni económicos ni costosos, Costosos, Muy costosos obteniéndose los resultados contenidos en el Anexo 5, resumidos en:

Boletos 2D: El 57,07\% opina que son "Económicos", un 25,13\% que no son "Ni económicos ni costosos", un 15,71\% que son "Muy económicos" y el 2,09\% que son costosos. No hubo respuestas de los encuestados que dijeran que les parecen "Muy costosos".

Boletos 3D: Un poco más de la mitad indicó que los precios de estos boletos le parecen "Económicos" representando un 55,76\% de los encuestados. E1 30,10\% por otra parte mencionó que los precios le parecen "Ni económicos ni costosos", el 10,21\% que son "Muy económicos", un $3,40 \%$ que son "Costosos" y apenas un $0,52 \%$ que le parecen "Muy costosos".

Combos del bar: El 49,48\% cree que los precios no son "Ni económicos ni costosos", el $36,91 \%$ que son "Económicos", el 10,73\% que son "Costosos", el 1,57\% dice que le parecen "Muy costosos" y un 1,31\% que son muy económicos".

La mitad de los encuestados señalan que los precios en el cine son Económicos o al menos Ni económicos ni costosos lo cual se podría considerar algo positivo por el hecho de que el sector se cree que puede ser sensible a precios y podría resultar positivo que se considere que los precios no son altos.

Tabla 1: Calificación sobre servicios generales del cine y boletería

\begin{tabular}{|c|c|c|c|c|c|c|c|c|c|c|c|c|c|c|c|c|}
\hline & \multicolumn{2}{|c|}{ Excelente } & \multicolumn{2}{|c|}{ Muy bueno } & \multicolumn{2}{|c|}{ Bueno } & \multicolumn{2}{|c|}{ Regular } & \multicolumn{2}{|c|}{ Malo } & \multicolumn{2}{|c|}{ Muy malo } & \multicolumn{2}{|c|}{ Pésimo } & \multicolumn{2}{|c|}{ No aplica } \\
\hline $\begin{array}{l}\text { Las películas que } \\
\text { ofrecen me parecen }\end{array}$ & 230 & $60,2 \%$ & 84 & $22,0 \%$ & 60 & $15,7 \%$ & 8 & $2,1 \%$ & 0 & $0,0 \%$ & 0 & $0,0 \%$ & 0 & $0,0 \%$ & 0 & $0,0 \%$ \\
\hline $\begin{array}{l}\text { Los horarios de las } \\
\text { películas que me gustan } \\
\text { me parecen }\end{array}$ & 216 & $56,5 \%$ & 105 & $27,5 \%$ & 55 & $14,4 \%$ & 6 & $1,6 \%$ & 0 & $0,0 \%$ & 0 & $0,0 \%$ & 0 & $0,0 \%$ & 0 & $0,0 \%$ \\
\hline $\begin{array}{l}\text { El tiempo que espero en } \\
\text { fila de boletería me } \\
\text { parece }\end{array}$ & 242 & $63,4 \%$ & 84 & $22,0 \%$ & 53 & $13,9 \%$ & 3 & $0,8 \%$ & 0 & $0,0 \%$ & 0 & $0,0 \%$ & 0 & $0,0 \%$ & 0 & $0,0 \%$ \\
\hline $\begin{array}{l}\text { La actitud de servicio y } \\
\text { cordialidad de los } \\
\text { cajeros de boletería me } \\
\text { parece }\end{array}$ & 227 & $59,4 \%$ & 94 & $24,6 \%$ & 47 & $12,3 \%$ & 14 & $3,7 \%$ & 0 & $0,0 \%$ & 0 & $0,0 \%$ & 0 & $0,0 \%$ & 0 & $0,0 \%$ \\
\hline $\begin{array}{l}\text { El tiempo de atención en } \\
\text { boletería una vez que } \\
\text { llego a la caja me parece }\end{array}$ & 245 & $64,1 \%$ & 102 & $26,7 \%$ & 32 & $8,4 \%$ & 3 & $0,8 \%$ & 0 & $0,0 \%$ & 0 & $0,0 \%$ & 0 & $0,0 \%$ & 0 & $0,0 \%$ \\
\hline $\begin{array}{l}\text { El tiempo que me dan } \\
\text { para poder ingresar a la } \\
\text { sala antes que empiece } \\
\text { la pelicula me parece }\end{array}$ & 247 & $64,7 \%$ & 83 & $21,7 \%$ & 49 & $12,8 \%$ & 2 & $0,5 \%$ & 1 & $0,3 \%$ & 0 & $0,0 \%$ & 0 & $0,0 \%$ & 0 & $0,0 \%$ \\
\hline $\begin{array}{l}\text { La limpieza en las salas } \\
\text { me parece }\end{array}$ & 239 & $62,6 \%$ & 91 & $23,8 \%$ & 48 & $12,6 \%$ & 4 & $1,0 \%$ & 0 & $0,0 \%$ & 0 & $0,0 \%$ & 0 & $0,0 \%$ & 0 & $0,0 \%$ \\
\hline $\begin{array}{l}\text { Siente que el Mall le } \\
\text { proporciona un nivel de } \\
\text { seguridad }\end{array}$ & 276 & $72,3 \%$ & 80 & $20,9 \%$ & 21 & $5,5 \%$ & 4 & $1,0 \%$ & 1 & $0,3 \%$ & 0 & $0,0 \%$ & 0 & $0,0 \%$ & 0 & $0,0 \%$ \\
\hline $\begin{array}{l}\text { Siente que el cine le } \\
\text { proporciona un nivel de } \\
\text { seguridad }\end{array}$ & 290 & $75,9 \%$ & 69 & $18,1 \%$ & 22 & $5,8 \%$ & 1 & $0,3 \%$ & 0 & $0,0 \%$ & 0 & $0,0 \%$ & 0 & $0,0 \%$ & 0 & $0,0 \%$ \\
\hline
\end{tabular}

Respecto al Servicio al cliente en general y boletería la mayor concentración de la calificación está entre un servicio excelente y muy bueno destacándose mucho más el 75,9\% de los consumidores que piensan que el cine les proporciona un excelente nivel de Seguridad personal, seguido por el 72,3\% que opina que el Mall le ofrece también un excelente nivel de seguridad y por último el $64,7 \%$ opina que es excelente el tiempo que se les da para poder ingresar a la sala antes que empiece la película. Un punto importante a destacar es que el 3,7\% indicó que la Actitud de servicio y cordialidad de los cajeros de boletería les pareció regular, esto considerando a que ninguna otra de las variables consultadas en el servicio de boletería llega al 
$3 \%$ en ser "Regular", entonces si la empresa desea destacarse por el servicio pero a ser igual un porcentaje bajo resultaría importante bajarlo a $0 \%$.

Tabla 2: Calificación sobre servicios en el área del bar

\begin{tabular}{|c|c|c|c|c|c|c|c|c|c|c|c|c|c|c|c|c|}
\hline \multirow[b]{2}{*}{$\begin{array}{l}\text { La temperatura de los } \\
\text { alimentos me parece }\end{array}$} & \multicolumn{2}{|c|}{ Excelente } & \multicolumn{2}{|c|}{ Muy bueno } & \multicolumn{2}{|c|}{ Bueno } & \multicolumn{2}{|c|}{ Regular } & \multicolumn{2}{|c|}{ Malo } & \multicolumn{2}{|c|}{ Muy Malo } & \multicolumn{2}{|c|}{ Pésimo } & \multicolumn{2}{|c|}{ No aplica } \\
\hline & 241 & $63,1 \%$ & 70 & $18,3 \%$ & 49 & $12,8 \%$ & 6 & $1,6 \%$ & 0 & $0,0 \%$ & 0 & $0,0 \%$ & 0 & $0,0 \%$ & 16 & $4,2 \%$ \\
\hline $\begin{array}{l}\text { El sabor del canguil que } \\
\text { ofrecen me parece }\end{array}$ & 181 & $47,4 \%$ & 92 & $24,1 \%$ & 71 & $18,6 \%$ & 12 & $3,1 \%$ & 1 & $0,3 \%$ & 0 & $0,0 \%$ & 0 & $0,0 \%$ & 25 & $6,5 \%$ \\
\hline $\begin{array}{l}\text { El sabor de los nachos } \\
\text { que ofrecen me parece }\end{array}$ & 190 & $49,7 \%$ & 78 & $20,4 \%$ & 59 & $15,4 \%$ & 11 & $2,9 \%$ & 0 & $0,0 \%$ & 0 & $0,0 \%$ & 1 & $0,3 \%$ & 43 & $11,3 \%$ \\
\hline $\begin{array}{l}\text { El sabor del hot dog que } \\
\text { ofrecen me parece }\end{array}$ & 177 & $46,3 \%$ & 88 & $23,0 \%$ & 47 & $12,3 \%$ & 15 & $3,9 \%$ & 1 & $0,3 \%$ & 0 & $0,0 \%$ & 0 & $0,0 \%$ & 54 & $14,1 \%$ \\
\hline $\begin{array}{l}\text { La variedad de productos } \\
\text { que ofrecen me parece }\end{array}$ & 240 & $62,8 \%$ & 72 & $18,8 \%$ & 43 & $11,3 \%$ & 13 & $3,4 \%$ & 0 & $0,0 \%$ & 0 & $0,0 \%$ & 0 & $0,0 \%$ & 14 & $3,7 \%$ \\
\hline $\begin{array}{l}\text { La actitud de servicio y } \\
\text { cordialidad de los } \\
\text { cajeros del bar me } \\
\text { parece }\end{array}$ & 237 & $62,0 \%$ & 80 & $20,9 \%$ & 42 & $11,0 \%$ & 6 & $1,6 \%$ & 0 & $0,0 \%$ & 0 & $0,0 \%$ & 0 & $0,0 \%$ & 17 & $4,5 \%$ \\
\hline $\begin{array}{l}\text { El tiempo que espero en } \\
\text { fila del bar me parece }\end{array}$ & 247 & $64,7 \%$ & 74 & $19,4 \%$ & 40 & $10,5 \%$ & 4 & $1,0 \%$ & 0 & $0,0 \%$ & 0 & $0,0 \%$ & 0 & $0,0 \%$ & 17 & $4,5 \%$ \\
\hline $\begin{array}{l}\text { El tiempo de atención del } \\
\text { bar una vez que llego a la } \\
\text { caja me parece }\end{array}$ & 255 & $66,8 \%$ & 73 & $19,1 \%$ & 36 & $9,4 \%$ & 3 & $0,8 \%$ & 0 & $0,0 \%$ & 0 & $0,0 \%$ & 0 & $0,0 \%$ & 15 & $3,9 \%$ \\
\hline Limpieza área bar & 264 & $69,1 \%$ & 75 & $19,6 \%$ & 28 & $7,3 \%$ & 6 & $1,6 \%$ & 0 & $0,0 \%$ & 0 & $0,0 \%$ & 0 & $0,0 \%$ & 9 & $2,4 \%$ \\
\hline
\end{tabular}

Siguiendo con el Servicio al cliente en el Bar, también se puede encontrar una mayor concentración a calificar de excelente y muy bueno el servicio recibido, siendo que el mayor puntaje en excelencia se destaca la Limpieza en el bar con un 69,1\% de respuestas, seguido de un $66,8 \%$ que categoriza de excelente el Tiempo de atención del bar una vez que llega a la caja y por último un $64,7 \%$ el Tiempo de atención que espera en la fila del bar que le ha parecido excelente. En cuanto a la parte negativa de la categorización de "Regular" hay tres tipos de servicio que destacan, siendo el primero con un 3,9\% el sabor del hot dog, seguido por un 3,4\% la Variedad de Productos que se ofrecen y un 3,1\% el sabor del canguil que también les ha parecido regular, considerando entonces que los mayores problemas en esta área no están enfocados al servicio en sí sino al producto habría que tomar medidas que contribuyan a mejorar estos aspectos.

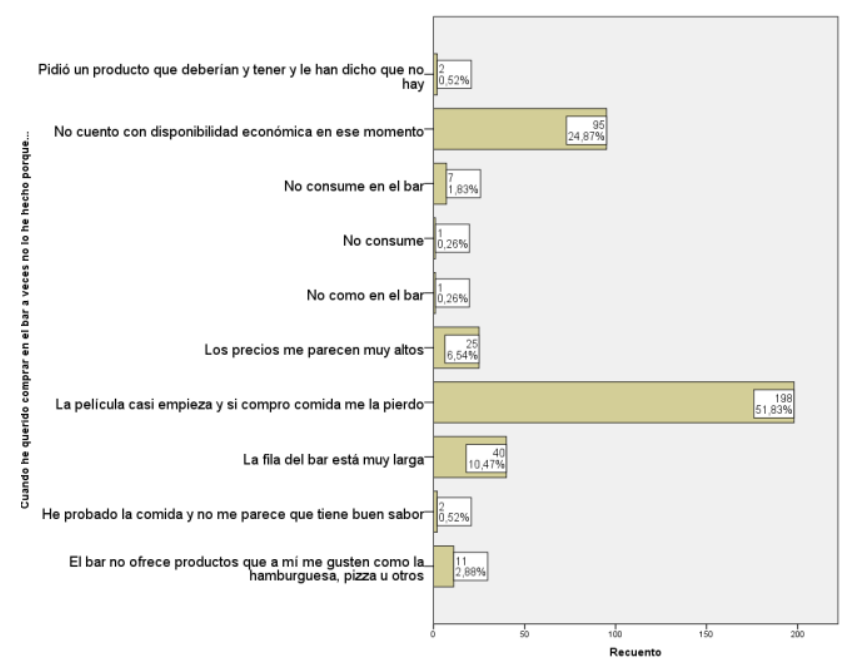

Figura 14: Cuando he querido comprar en el bar a veces no lo he hecho porque...

El mayor problema que ha sentido el encuestado al querer comprar en el bar y no ha podido fue porque si compra se pierde la película, esto lo menciona un 51,83\% de los encuestados, caso que la empresa debería tomar muy en cuenta para ayudar al cliente con el tiempo oportuno para hacer la compra, lo que a su vez se traduce en recompensas económicas 
para el cine. El 24,87\% también es una cifra oportuna para revisar considerando que esta cantidad de personas mencionan que las veces que no han comprado en el bar han sido porque no han tenido disponibilidad económica, caso que sí es más difícil de controlar para el cine.

Otro aspecto que es relevante para la empresa, es conocer la efectividad de la comunicación de las promociones o beneficios que hasta el momento se han realizado, siendo así, se consultó a los encuestados obteniendo los siguientes resultados por promoción o beneficio, se explicará brevemente la mecánica de la promoción y la forma en que fue comunicado:

- Cartilla 2x1, había una promoción con una cuponera con divisiones para cuatro tickets de 2x1, una vez que el cliente usaba sus cuatro cupones podía depositar la cartilla con sus datos en un ánfora para participar por premios. Los medios de comunicación utilizados fueron vía redes sociales, una valla ubicada en Guayaquil, comunicación en interiores y exteriores del Mall El Fortín.

Mediante la encuesta se obtuvo que el $72,51 \%$ de los encuestados no se enteró de la promoción pero sí le gusta la idea de ella, un $27,23 \%$ sí se enteró y le gustó la promoción y el 0,26\% dice que se enteró peero no le gustó.

- Día Máximo, consiste en un precio de $\$ 2$ para entradas en formato 2D y \$3,50 para formatos en 3D. Esta promoción tiene lugar desde el 2014, lo que le ha dado la posibilidad de que pese a no ser comunicada por radios o medios muy masivos ya es altamente conocida teniendo un $87,96 \%$ de encuestados quien les gusta y conocen la promoción. El medio de comunicación más usado ha sido redes sociales como Facebook con posteos semanales y publicidad impresa en interiores y exteriores del Mall El Fortín y mediante los propios boleteros del cine.

- Descuento de \$1 con la tarjeta Cinema Club, consiste en una tarjeta gratuita que permite tener un beneficio de $\$ 1$ de descuento en películas formato $2 \mathrm{D}$ y $3 \mathrm{D}$ y el $10 \%$ en prodcutos del bar. El medio de comunicación más usado es mediante material publicitario impreso y digital colocado en los interiores y exteriores de Mall El Fortín. Existe un 41,10\% de los encuestados que se enteraron de este beneficio siendo mayo el grado de desconocimiento $58,90 \%$ que mencionaron que no se enteró pero sí le gusta el beneficio.

- Maxbillete, es una promoción que se realizó en Septiembre de 2014 y que se repitió en 2015, consistía en unos cupones en forma de billetes de un dólar que permitían un descuento de hasta $\$ 2$ en entradas y combos del bar. El medio de difusión masiva más utilizado fue en las radios más representativas del target mediante menciones y horarios dedicados, redes sociales como Facebook con varios posteos semanales, publicidad impresa en interiores y exteriores del Mall El Fortín, volanteo, perifoneo y publicidad interna en el cine. El nivel de conocimiento y que les gusta la promoción está en un 90,84\% de los encuestados, siendo apenas un 9,16\% de personas que no la conocieron pero sí les gusta la idea.

- Vacaciones de Película, fue una promoción que se desarrolló durante febrero a marzo de 2015, en la que se entregaban de dos cupones uno para recarga de canguil y gaseosa gratis y otro en que el segundo boleto salía a mitad de precio. Se utilizó radio pero estas se diversificaron y horarios no dedicados, adicional redes sociales como Facebook con varios posteos semanales, publicidad impresa en interiores y exteriores 
del Mall El Fortín, volanteo, perifoneo y publicidad interna en el cine. El 81,68\% de los encuestados no se enteró de la promoción pero le gusta, llegando apenas a un $18,06 \%$ de los encuestados que sí se enteró y sí le gustó la promoción, habiendo un $0,26 \%$ que indicó que sí se enteró pero no le gustó.

Todas las promociones parecen ser atractivas para los encuestados, sin embargo la comunicación ha sido más efectiva para ciertas promociones.

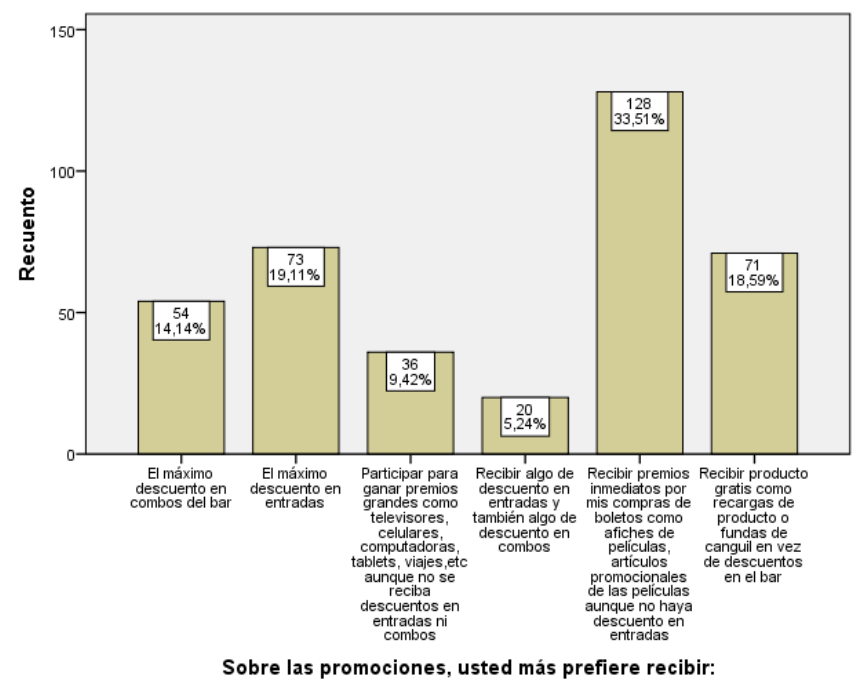

Figura 15: Sobre las promociones, usted prefiere recibir

En virtud de conocer lo que para los consumidores es más atractivo en cuanto a promociones se desarrolló una pregunta sobre las preferencias de las mismas obteniéndose que el $33,51 \%$ de los encuestados prefieren no recibir descuentos en las entradas, pero sí obtener premios inmediatos por sus compras de boletos tales afiches de películas, artículos promociones de ellas. El 19,11\% sí prefieren el máximo descuento en entradas, seguido del 18,59\% que prefieren recibir producto gratis como recargas de fundas de canguil en vez de descuentos en el bar, un 14,14\% que prefiere el máximo descuento en combos del bar, el 9,42\% prefiere participar para ganar premios grandes como televisores, celulares, computadoras, tablets, viajes, etc. aunque no reciba descuentos en entradas ni combos y por último el 5,24\% prefiere recibir algo de descuento en entradas y también algo de descuento en combos.

Tabla 3: Atributos más valorados por los consumidores 


\begin{tabular}{|c|c|c|c|c|c|c|c|c|c|c|}
\hline & 1 & 2 & 3 & 4 & 5 & 6 & 7 & 8 & 9 & Total \\
\hline \multirow[t]{2}{*}{ Promociones atractivas } & 125 & 64 & 39 & 38 & 32 & 20 & 27 & 16 & 21 & 382 \\
\hline & $32,7 \%$ & $16,8 \%$ & $10,2 \%$ & $9,9 \%$ & $8,4 \%$ & $5,2 \%$ & $7,1 \%$ & $4,2 \%$ & $5,5 \%$ & $100 \%$ \\
\hline \multirow{2}{*}{$\begin{array}{l}\text { Comodidad de las } \\
\text { intalaciones }\end{array}$} & 31 & 119 & 69 & 40 & 23 & 33 & 24 & 17 & 26 & 382 \\
\hline & $8,1 \%$ & $31,2 \%$ & $18,1 \%$ & $10,5 \%$ & $6,0 \%$ & $8,6 \%$ & $6,3 \%$ & $4,5 \%$ & $6,8 \%$ & $100 \%$ \\
\hline \multirow{2}{*}{$\begin{array}{l}\text { Tienen las películas que } \\
\text { me gustan }\end{array}$} & 30 & 40 & 123 & 55 & 32 & 33 & 22 & 23 & 24 & 382 \\
\hline & $7,9 \%$ & $10,5 \%$ & $32,2 \%$ & $14,4 \%$ & $8,4 \%$ & $8,6 \%$ & $5,8 \%$ & $6,0 \%$ & $6,3 \%$ & $100 \%$ \\
\hline \multirow[t]{2}{*}{ Atención al cliente buena } & 11 & 34 & 26 & 93 & 83 & 51 & 29 & 27 & 28 & 382 \\
\hline & $2,9 \%$ & $8,9 \%$ & $6,8 \%$ & $24,3 \%$ & $21,7 \%$ & $13,4 \%$ & $7,6 \%$ & $7,1 \%$ & $7,3 \%$ & $100 \%$ \\
\hline \multirow{2}{*}{$\begin{array}{l}\text { Precios convenientes en } \\
\text { boletos] }\end{array}$} & 22 & 21 & 32 & 45 & 96 & 73 & 42 & 29 & 22 & 382 \\
\hline & $5,8 \%$ & $5,5 \%$ & $8,4 \%$ & $11,8 \%$ & $25,1 \%$ & $19,1 \%$ & $11,0 \%$ & $7,6 \%$ & $5,8 \%$ & $100 \%$ \\
\hline \multirow{2}{*}{$\begin{array}{l}\text { Precios convenientes en } \\
\text { productos del bar }\end{array}$} & 21 & 10 & 22 & 16 & 18 & 28 & 59 & 95 & 113 & 382 \\
\hline & $5,5 \%$ & $2,6 \%$ & $5,8 \%$ & $4,2 \%$ & $4,7 \%$ & $7,3 \%$ & $15,4 \%$ & $24,9 \%$ & $29,6 \%$ & $100 \%$ \\
\hline \multirow[t]{2}{*}{ Cercanía a mi hogar } & 91 & 38 & 22 & 30 & 35 & 66 & 40 & 27 & 33 & 382 \\
\hline & $23,8 \%$ & $9,9 \%$ & $5,8 \%$ & $7,9 \%$ & $9,2 \%$ & $17,3 \%$ & $10,5 \%$ & $7,1 \%$ & $8,6 \%$ & $100 \%$ \\
\hline \multirow{2}{*}{$\begin{array}{l}\text { Calidad en productos del } \\
\text { bar }\end{array}$} & 22 & 27 & 14 & 26 & 23 & 24 & 48 & 124 & 74 & 382 \\
\hline & $5,8 \%$ & $7,1 \%$ & $3,7 \%$ & $6,8 \%$ & $6,0 \%$ & $6,3 \%$ & $12,6 \%$ & $32,5 \%$ & $19,4 \%$ & $100 \%$ \\
\hline \multirow{2}{*}{$\begin{array}{l}\text { Calidad de sonido e } \\
\text { imagen en la sala }\end{array}$} & 29 & 29 & 35 & 39 & 40 & 54 & 91 & 24 & 41 & 382 \\
\hline & $7,6 \%$ & $7,6 \%$ & $9,2 \%$ & $10,2 \%$ & $10,5 \%$ & $14,1 \%$ & $23,8 \%$ & $6,3 \%$ & $10,7 \%$ & $100 \%$ \\
\hline \multirow[t]{2}{*}{ Total } & 382 & 382 & 382 & 382 & 382 & 382 & 382 & 382 & 382 & 382 \\
\hline & $100 \%$ & $100 \%$ & $100 \%$ & $100 \%$ & $100 \%$ & $100 \%$ & $100 \%$ & $100 \%$ & $100 \%$ & $100 \%$ \\
\hline
\end{tabular}

Se realizó una consulta a los encuestados consultándole la valoración del 1 al 9 sobre los atributos que lo han motivado a ir a Max Cinema, siendo 1 el atributo más importante y 9 el menos valorado, obteniendo el siguiente orden de importancia: En primer lugar el atributo más valorado son las "Promociones atractivas" obteniendo un 32,70\%, en segundo lugar el más puntuado es la "Comodidad de las instalaciones" con el 31,20\%, en tercer lugar el 32,20\% opina que el motivo es que "Tienen las películas que me gustan", en cuarto lugar con el 24,30\% por la "Atención al cliente buena", en quinto y sexto lugar prevaleció con un 25,10\% y 19,10\% respectivamente los "Precios convenientes en boletos", en séptimo lugar está el 23,80\% la "Calidad de sonido e imagen en la sala", en octavo lugar con el 32,50\% la "Calidad en productos del bar" y en noveno lugar el 29,60\% los "Precios convenientes en productos del bar".

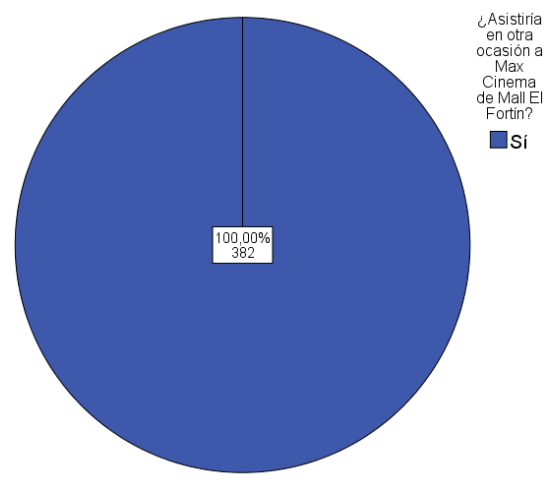

Figura 16: ¿Asistiría en otra ocasión a Max Cinema?

Un dato interesante es que el $100 \%$ de los encuestados manifestaron que regresarían a Max Cinema, lo que sugiere una aceptación ante la marca de cines a pesar de cualquier desacuerdo con productos o servicios recibidos.

\section{Resultados Investigación Cualitativa}

Según los resultados obtenidos por la investigación cuantitativa, el 44,50\% de la población encuestada y que representan la mayor cantidad de la población de clientes de este 
cine son los Estudiantes, es por ello que se decidió realizar una entrevista a profundidad a uno de ellos y conocer a con más detalle su estilo de vida, sus hábitos, entretenimientos, si sus papás lo apoyan económicamente, la cantidad de personas con las que suele venir al cine, sus motivadores de consumo, el momento de decisión para ir al cine, la experiencia que se ha llevado con esta marca de cines y la competencia, si se enteró de las promociones, su apego o posible fidelidad a la marca y la percepción que tiene de ella si esta fuera una persona.

A continuación, un resumen de la entrevista:

$\checkmark$ Nombre del entrevistado: Francisco Omar Marcillo

$\checkmark$ Edad: 19 años

$\checkmark$ Perfil: Está en proceso para aprobar los cursos de nivelación y optar por una beca universitaria del Estado.

$\checkmark$ Lugar de residencia: Guayaquil, zona de Vergeles, vive con sus padres, hermanos y abuelo, lleva en esa casa casi toda su vida, la vivienda es propia.

$\checkmark$ Padres: Papá inspector en FADESA y madre es ama de casa. Padre tiene trabajos rotativos por lo que a veces trabaja fines de semana.

$\checkmark$ Hermanos: Tiene dos hermanos de 17 y 18 años.

$\checkmark$ Movilización: poseen carro los papás

$\checkmark$ Rutina diaria: Pasa en casa, hace quehaceres domésticos, cuidada a su abuelo.

$\checkmark$ Entretenimientos: Viajar en familia a la Sierra a unos balnearios, complejos deportivos, parque samanes en bicicleta o caminar.

$\checkmark$ Definición de un cine: Es un lugar de entretenimiento donde se puede ir a ver películas, donde antes se podían ver obras de teatro.

$\checkmark$ Qué busca al ir a un cine: Busca estar en los grandes estrenos, los que ha estado esperando bastante tiempo para verlos en pantalla grande, no los vería en televisión o internet porque dice que las películas salen mal grabadas con ruidos que no permiten verla bien.

$\checkmark$ Tipos de película que le gustan ver: Ciencia Ficción, acción, comedia o basados en hechos de la vida real, en esta última pueden ser historias de terror o románticas.

$\checkmark$ Cómo se siente al venir al cine Max Cinema: se siente bien porque es cómodo, los asientos están numerados.

$\checkmark$ Motivador para ir al cine: Por los estrenos y la calidad de las películas

$\checkmark \quad$ ¿Le gusta que haya gente o no en el cine? Si está vacía la sala tiene la impresión de haber elegido mal la película, le parece deprimente. Pero si hay muchas personas lo que le incomodan a veces son los niños que hacen bulla o andan por la sala, comentó una anécdota que un niño un día le pidió canguil que he había comprado, además que pateó el asiento.

$\checkmark$ Con quienes asiste al cine: Va con pocos amigos, unas amigas o a veces con las hermanas o familia. $50 \%$ de las veces asiste con amigos y la otra mitad con familia. No va ir en grupos grandes de amigos le ha provocado que casi los saquen del cine porque llevaban comida de afuera.

$\checkmark$ Ocasiones de decisión para ir al cine: Investiga previamente las películas que van a estrenar para ir el primer día, casi no es espontáneo.

$\checkmark \quad$ ¿Quién elige la película? En este caso él decide y él busca previamente la película que desean ver porque su acompañante dice que él paga así que él elige. 
$\checkmark$ Financiamiento para el entretenimiento: El papá es quien le proporciona dinero para salir, no le da mesada pero les da dinero para cada salida y esto es dependiendo al lugar donde va les da el dinero necesario. Cuando sale con hermanas no le da dinero completo para la comida del bar del cine pero le da una parte y él debe compartir gastos con la otra persona para comprar su comida.

$\checkmark$ Cines de elección y preferencia: Max Cinema es su cine más visitado desde que se creó porque dice que desde la construcción del Mall vio un banner que decía Max Cinema y quiso probar qué tal era.

$\checkmark$ Experiencia en Max Cinema: Desde el inicio vino a probar un lugar nuevo, los precios le parecían más convenientes que otros cines, más ofertas.

$\checkmark$ Movilización al cine: Viene en un bus, la 118 lo trae directo al Mall, camina a la autopista Terminal-Pascuales para tomarlo, llega entre 8 a 10 minutos. De regreso sólo la 118 es la única línea que lo deja cerca a su casa. A las 6:30pm ya debe salir del Mall porque se hace obscuro y le parece ya peligroso. Comenta que la Perimetral (donde está ubicado el cine) ya de noche es peligroso ya que ha sido testigo de varios robos en los buses.

$\checkmark$ A veces el papá lo trae en su carro cuando está libre.

$\checkmark$ Experiencia en los otros cines: Comenta que amistades vivieron una experiencia molesta en Cinemark de Mall del Sol, ellos tienen la impresión que la película se proyecta por medio de una señal que viene del extranjero porque una vez vieron borrosa la película y que el personal del cine les dijo que era una cuestión de la señal.

$\checkmark$ Hace un año un amigo de la hermana pasó otra mala experiencia que cree fue en el mismo cine pero otra ubicación, dice que la película nunca se proyectó y que le tuvieron que devolver el dinero.

$\checkmark$ Sabor de la comida del bar: le ha gustado, le parece que son similares los productos a los de los otros cines.

$\checkmark$ Opinión del servicio: Ha sentido que es una buena atención, el tiempo en fila prudente, el personal de boletería lo ha tratado bien y le han brindado la información que necesita.

$\checkmark$ Sin embargo en bar dice que los clientes a veces se demoran en decidir qué comprar y se ha sentido asustado porque ya falta poco para empezar la película y la fila del bar no avanza.

$\checkmark$ Sobre la ubicación del cine en el Fortín: Le parece que es un poco alejada del centro de la ciudad pero en tiempo está bien, le parece más cerca que otros cines, por la autopista no hay tráfico.

$\checkmark$ Sobre la competencia: No le ha gustado que ha ido a Supercines del Riocentro Norte y los 2x1 no son para todas las películas, en cambio en Max Cinema que ha ido los jueves el 2x1 (que en realidad es el Día Máximo y cada entrada cuesta \$2) sí aplica para todas las películas. Otra experiencia negativa respecto a los otros cines es que ha llegado a ventanilla y no ha encontrado asientos, teniendo que ir a otros cines a buscar para ver una película en particular.

$\checkmark$ Sobre Max Cinema: Siente que siempre encuentra las promociones por eso lo prefiere. Ha visto que es un cine limpio tanto en salas como baños. Los costos del bar le parecen un poco más económicos que en otros cines y la cantidad de comida es casi la misma.

$\checkmark$ Comunicación de las promociones: se enteró por Facebook, página del cine. Visita la página del Facebook del cine cuando sabe que hay trivias y conoce que son los lunes y que los martes repiten la trivia. 
$\checkmark$ Sobre las promociones: Le han gustado más la del Día Máximo que es el jueves porque es como si fuera un $2 \mathrm{x} 1$ y hasta más barato. Sí conoció más de dos promociones del cine y le han gustado beneficios como las recargas de canguil y gaseosa porque sabe que en otros lugares cobran ese beneficio. Le gustó en Segundo boleto a mitad de precio porque no necesariamente tenía que ir el jueves, podía ir otro día.

$\checkmark$ Si le ponen otro cine al lado de otra marca: él dice que iría a comparar los precios. Aunque le importan más los precios de boletos que de la comida.

$\checkmark$ Cómo se sentiría si Max Cinema desapareciera: Tendría que buscar su antigua rutina u otro cine nuevo que le ofrezca algo similar en precios que Max Cinema porque está acostumbrado a precios buenos.

$\checkmark$ Max Cinema como persona, descripción: Como una persona de negocios con un traje de apariencia adulta, madura de 30 a 35 años, hombre de familia, sí puede confiar en él porque le ha dado tanto entretenimiento, le agradecería por todo lo que ha hecho.

\section{Conclusiones}

Según datos obtenidos en las encuestas realizadas, se puede destacar de manera primordial el perfil del principal consumidor del cine obteniendo que, en su mayoría se trata de jóvenes de hasta 35 años de edad, de los cuales más de la mitad no tienen hijos, viven en zonas aledañas al Fortín, asisten al cine en su mayoría al menos una vez al mes normalmente acompañados, les gusta variar y sus horarios preferidos para ir son de 5 a $8 \mathrm{pm}$.

Los consumidores, mediante las encuestas y entrevista a profundidad, manifestaron que las promociones, las instalaciones y las películas que se proyectan resultan de mayor incentivo para asistir a este cine. Las promociones actúan entonces como principal motivador de compra para esta marca, siendo nombrado también en la entrevista a profundidad como un atributo de alta importancia dada la conveniencia en precios y beneficios que le ha proporcionado en comparación con los otros cines, en los que incluso se ha llevado malas experiencias dado que ha aplicado restricciones.

Mediante las encuestas se pudo observar un porcentaje alto de consumidores que viven cercanos al cine, para lograr una ventaja competitiva uno de los factores que se puede considerar es el canal de ventas. Las empresas pueden conseguir su ventaja competitiva al diseñar la cobertura, la capacidad y el funcionamiento de sus canales de distribución (Kotler y Keller, 2006, p.320). Para este cine resulta de alta relevancia su ubicación, atendiendo a un mercado amplio que inicialmente debía movilizarse a otros sectores más alejados, por tanto, esta cercanía de su canal de ventas representa en sí una estrategia de marketing que podría llegar a ser más fuerte si considera desarrollar una cadena de cines en otras zonas con similares condiciones al segmento de mercado actual tanto en la misma u otras ciudades. Sin embargo, considerando que las promociones resultaron ser también altamente valoradas, podrían manejarse como otro de sus factores diferenciadores pero largo plazo, manteniendo la línea creativa innovadora, promociones que no representen confusiones o restricciones para el cliente.

Analizando las promociones ya realizadas, es importante destacar que apenas dos de ellas fueron altamente conocidas y recordadas por los encuestados, por tanto, la labor de comunicación resulta muy importante para poder destacar este beneficio como único y diferenciador a través de los medios más utilizados por su mercado objetivo. 
El posicionamiento de marca, puede realizarse considerando diferentes grados de beneficios a diferentes niveles de precios, siendo así que el posicionamiento estratégico que le conviene a este cine es, ofrecer "Más beneficios por el mismo precio". Las empresas pueden atacar el posicionamiento de un competidor de más por más mediante la introducción de una marca que ofrezca calidad comparable a un menor precio (Kotle y Armstrong, 2013, p.264). El efecto de ofrecer promociones únicas puede representar para este mercado un valor agregado, por tanto, sentir un mayor nivel de beneficios respecto a la competencia aunque paguen relativamente lo mismo que ellos.

Respecto a las estrategias en producto (servicio), se recomienda analizar a profundidad el servicio al cliente entregado por cada persona de línea de contacto debido a que algunos consumidores manifestaron una atención regular en cuanto a Actitud y cordialidad de los cajeros de boletería.

Por último, se recomienda realiza (Kotler \& Armstrong, Fundamentos de Marketing, 2013)r una investigación más exhaustiva a mercados alternos que ya los visitan como personas que viven en la Vía Terminal Pascuales, Vergeles, Orquídeas, Mucho Lote1 y urbanizaciones de Vía Daule, dado que al momento ellos representan alrededor del 8\% de sus clientes actuales según encuestas. Esto les permitirá conocer la predisposición a asistir a este cine o identificar factores necesarios para que estos consumidores se sientan atraídos por probar esta nueva marca, lo que podría ayudar a incrementar sus ventas y por tanto una mayor porción de mercado.

\section{Bibliografía}

Alonso, J., \& Grande, I. (2004). Comportamiento del consumidor: desiciones y estrategia de marketing (5ta edición ed.). Madrid: ESIC Editorial.

Alonso, J., \& Grande, I. (2012). Comportamiento del Consumidor Decisiones y Estrategia de Marketing. México D.F.: ESIC Editorial.

Armstrong, G., \& Kotler, P. (1996). Fundamentos de Marketing. Pearson.

Arribas, M. (2004). Diseño y validación de cuestionarios. Matronas Profesión, 23-29.

INEC, I. N. (Diciembre de 2011). Encuesta de Estratificación del Nivel Socioeconómico NSE 2011. Recuperado el 09 de febrero de 2016, de http://www.inec.gob.ec/estadisticas/?option=com_content\&view=article\&id=112\&Itemid $=90 \&$

Kotler, P., \& Amstrong, G. (2001). Marketing. México: Pearson Educación.

Kotler, P., \& Armstrong, G. (2013). Fundamentos de Marketing. México: Peason Educación.

Kotler, P., \& Keller, K. (2006). Dirección de Marketing. México: Pearson Educación. 
Levy, A. (1998). Marketing Avanzado: Un enfoque sistemático y construtivista de lo estratégico y de lo táctico. Barcelona, España: Ediciones Granica S.A.

Lovelock, C., \& Wirtz, J. (2009). Marketing de Servicios. Personal, tecnología y estrategia. México: Pearson Educación de México S.A. de C.V.

Malhotra, N. K. (2004). Investigación de Mercados, Un enfoque aplicado. México: Pearson Educación.

Quintanilla, I., Berenguer, G., Gómez, M. Á., \& Mollá, A. (2014). Comportamiento del Consumidor. Barcelona: Editorial UOC (Oberta UOC Publising, SL).

Solomon, M. R. (2013). Comportamiento del Consumidor. Naucalpan de Juárez, Estado de México: Pearson.

Subsecretaría de Hábitat y Asentamientos Humanos, (. (Agosto de 2011). http://www.habitatyvivienda.gob.ec/. Recuperado el 02 de Diciembre de 2015, de Intervención Urbana Integral En La Zona De Expansión Del Noroeste De La Ciudad De Guayaquil, $\quad$ Ecuador: http://www.habitatyvivienda.gob.ec/wpcontent/uploads/downloads/2014/01/6.-Intervenci\%C3\%B3n-Urbana-Intergral-NOGuayaquil.pdf 